\title{
Conceptions of Philosophy: Entering a Contested Grassland
}

\author{
Dr Amasa Philip Ndofirepi \\ Postdoctoral Fellow, Faculty of Education, University of Johannesburg, Johannesburg, South Africa \\ Email: amandochi@gmail.com
}

\section{Doi:10.5901/mjss.2014.v5n10p587}

\section{Abstract}

In this conceptual paper I enter the contested field of the notion of philosophy, which in itself, is an old and complex philosophical problem. Philosophers have characterized philosophical reflection by its notorious inconclusiveness. I metaphorically situate the conceptions of philosophy as a fertile pasture in which philosophers of different shades contest for a defensible meaning of philosophy. I explore four perspectives of philosophy as 1) the worldview or personal attitude, 2) an activity or an academic discipline of study, 3) universal or 4) particular /cultural. I attempt to survey and analyse the different schools of thought in an effort to provide a balanced view of the notion.

Keywords: questioning, inquiry, worldview, process, universalism, particularism

Not asking certain questions is pregnant with more dangers than failing to answer the questions already on the official agenda; while asking the wrong kind of questions all too often helps avert eyes from the truly important issues. The price of silence is paid in the hard currency of human suffering (Bauman, 1998, p. ix).

\section{Introduction}

The question, what is philosophy, is a reflexive one. It is about philosophy, provoked by philosophers themselves and represents an old and complex philosophical problem. Due to the complexity, each time philosophers attempt to discover what it is, they inevitably emerge with a new way of dealing with it, which is actually one way of doing philosophy. As a result, philosophy itself has traditionally been a considerable controversy. In effect, philosophy "is its own first problem" (Lucas, 1969, p. 1) and there is no other discipline that continues to question itself the way philosophy does. One of the central questions is: Is philosophy a body of knowledge? Whatever it is, there are several questions that emanate from this. Divergent views as to what philosophy is, what it offers man and what it aspires to do dominate all debates that are said to be philosophical. The philosophy question is therefore a vexing philosophical issue that resists every attempt to answer it in a definitive manner. Philosophical reflections are notorious for their inconclusiveness. However, philosophy can also be approached from different viewpoints. including:

Perhaps the question "what is philosophy" could be resolved by engaging ourselves in a family of questions,

- What activity is properly referred to as philosophising?

- What sort of a person is actually called a philosopher?

- What sort of tradition is properly called a tradition of philosophising?

- Can a thought system be justifiably called a philosophy or a philosophical system?

In addition to the above questions that seek to define the boundaries of what fits into the scope of philosophy, Janz (2004) questions the role of place as a criterion of philosophy. He asks:

- Is philosophical thought unaffected by the place in which it is practised?

- Can philosophy be conducted "in place"?

- Are there inhospitable places for philosophy...? (for example) a refugee or concentration camp?

- Is philosophy appropriate to all places? (and)

- Can philosophy attend to a place and still remain philosophical (p. 104)?

In the context of this paper, each approach will be considered as a supplement of the other and not as its contradiction and, as such, each will assist in making clear the diversity in meaning of philosophy and what different philosophers may say about the nature and function of philosophy. An attempt will be made to explore the meaning of philosophy. In order to do this, the three functions of philosophy, that is, the normative, the descriptive and the analytic will be explored. Also to be examined is the controversy surrounding philosophy as universal or cultural/particular practice. Given the brief charaterisation of the concept of philosophy, I hope to explore in this paper the nature and aim of philosophy before considering the two main conceptions of philosophy, that is, 1) philosophy as a worldview or personal attitude 2) philosophy as an activity and philosophy as an academic discipline of study. 


\section{The Nature and Character of Philosophy}

Philosophy itself suggests an array of theoretical approaches (Blackburn, 2004). Some essentialist thinkers acknowledge that great scholarly works such as Plato's Republic orDescartes' Meditations count as philosophy, who by laying down a definition, create a permanent and universal conception so that whatever lies within is philosophy and what is without is not. Others who hold on to the academic definition believe that philosophy is whatever is produced by people paid as philosophers in university faculties. The extreme approach is one that proposes that any text that gets read as philosophy counts as philosophy. In a way, the latter approach submits to the conviction that philosophy lies in the eye of the beholder. I find the latter problematic in that no two philosophers will agree on either the nature or status of philosophy that borders the definition. In support of the above, Anyanwu has put forward the position that those who seek to determine what philosophy is with one and only definition, are misguided. Thus he writes:

Most people who ask about the definition of philosophy find out that different philosophers give different definitions of it, and that such definitions are conflicting and contradictory. The innumerable definitions...seem to betray the preferences of each philosopher and to show the impossibility of offering a simple definition...or having one philosophy acceptable to all men, in all cultures and at all times... (Anyanwu, 2000, p. 126).

The significant character that is explicit in the above quotation is the elusiveness of the definition. Besides, Anyanwu observes that the enterprise of philosophy is characterised by the inconclusiveness of philosophical issues and reflections. Without a specific subject matter and therefore lacking a particular area of investigation, philosophy makes it difficult to tie itself to any exclusive and specific sphere. Hence, it is a philosophical problem to show outright distinctions between philosophical and non-philosophical discourses. Due to the numerous complexities of the notion, philosophy has come to be misunderstood by many. This could be attributed to wide misconception about its nature, purpose, methods, and relevance to public affairs in particular and human purposes in general.

Philosophy is not a fixed body of knowledge but is rather a continuous, ongoing reflective process as will be defended in the later parts of this paper. In addition, philosophy is dynamic and not static and changes with time in terms of its content and character. While the past has often defined philosophy in terms of wisdom, science, analysis, critique etc., and has been practised in different locales, for example the market place, churches and universities, this historical dimension is overtaken by the definition of philosophy as a mental activity. Yes, we might find it difficult to define philosophy by referring to its nature but we can understand the nature of philosophy by referring to it as an attitude of the mind, its source and its aim.

The etymological meaning of philosophy, derived from the Greek composite philosophia, is the 'love of wisdom'. Love is named initially to underscore a craving and striving to accomplish wisdom. This involves the passion to begin and sustain questioning things that are taken for granted. Thus, the continued quest for knowledge; its passionate search, and not its possession, is the essence of wisdom. As a result, philosophy becomes an inquisitive attitude of the mind. Philosophy thus is cognitive and conceptual since its content involves "...the exploration of the most basic ideas and problems of everyday life..." and is meta-cognitive in content since the process is about "improving one's own thinking and reasoning..." (Fisher, 1996, p. 1). But the question is: What is the source of philosophy? Do all people, of different races and ages, develop an inquisitive attitude?

The initial source of philosophical questioning is the sense of wonder - a sort of childlike wonder about just about everything. Even among the ancient philosophers from Socrates, Plato to Aristotle there is consensus that wonder, puzzlement, astonishment and amazement mark the starting point of philosophy. Plato puts the following words in Socrates as he writes," I see, my dear Theaetetus, that Theodorus had a true insight into your nature when he said that you were a philosopher, for wonder is the feeling of a philosopher, and philosophy begins in wonder" (Plato, 155d, p. 37). Aristotle echoes the Theaetetus in Metaphysics: "It was their wonder, astonishment that first led men to philosophise and still leads them (Aristotle, 982b ). For Plato, wonder refers to curiosity, to questioning and to seeking an answer to the questions raised by life. Doubt as a condition between belief and disbelief, involves indecision or mistrust of a supposed truth, an action, a motive, or a decision. Wonder involves the state of being curious and being in doubt. When we start to doubt that we do not fully understand and have not fully justified our basic beliefs about the world, we begin to philosophise. In this sense wonder, doubt and philosophy are connected, with wonder being a necessary condition for philosophy. In reiterating the role of "wonder" in the activity of philosophy, Omoregbe (1998) observes the following: ...the first step in the philosophical activity is this "wonder" that accompanies man's contact with himself or the world around him. This wonder gives rise to some fundamental questions and this is the second step. The third step is taken when man begins to reflect on these fundamental questions in search of answers. At this stage, the man in question is philosophising... (p. 3).

Amazement and bewilderment form the basis on which philosophers devise and formulate the what and why questions in a bid to have comprehension of the problem at hand. Questions are the first instrument in the philosopher's 
arsenal with which he or she works. It is out of the workings of an inquiring mind that philosophy emerges. It also becomes known out of human intellectual curiosity to transcend common sense. Philosophy, as Russell (2005) puts it "...keeps alive our sense of wonder by showing familiar things in an unfamiliar aspect" (p. 37). However, if everything on which philosophy lays a hand changes its nature from known to unknown, then what does philosophy aim for?

Philosophy aims at understanding and enlightenment rather than providing short conclusive answers. While searching for truth, philosophy does not close out new evidence but rather the search is perpetual striving for new insights. When comparing philosophical inquiry and scientific inquiry, one observes that the latter seeks knowledge that provides specific answers while the former enters by searching for answers on the residual questions that the former has failed to address. However, both attempt to provide answers, though science will end at a point where empirical evidence provides the answers while philosophy will theorise about the general implications of the evidence. The central concern of philosophy is to attend to insoluble questions for example, "what is life?" "Does reality exist?" "What is to know?" If the central concern of philosophy is the pursuit of questions that scientific inquiry has to answer then the empirical world would query the excitement of the enterprise of philosophy? If it is so complex, abstract and mentally unsettling, is it suitable for everyone, including children? I argue that philosophy increases our understanding of the problem at hand. It is by remaining curious and asking questions about the commonplace and the assumed knowledge that we keep theoretical knowledge alive. Philosophy as a critical activity of the mind comes alive regardless of its non-committal to provide definitive answers. The above characterisation provides the goal of philosophy as the enlargement of selfcontemplation of the infinity of the universe - what Russell (2005) calls "contemplative vision or speculation". Nevertheless, if this is what a philosophical activity involves, then do all people philosophise, including children? In the next section, I discuss the two conceptions of the notion of philosophy, namely the worldview conception and the process view of it.

\section{Conceptions of Philosophy}

As discussed in the section above, to do philosophy is to ask questions of a special kind about central human problems and then to grapple with them in a rigorous and meticulous way. Some conceive philosophy as a worldview; "...an accumulation of contents or products" (Estarellas, 2007 n.p.), and others an activity or a process - what Pecorino (1985) refers to as the "process view" $(p$.80). The nature and character of each will be explored in the sections below coupled with their critique.

\subsection{The worldview conception of philosophy}

The popular saying that "each of us has a philosophy" and "my philosophy is..." reflects the conception of philosophy as a worldview. Such a definition suggests "worldview" as a general view of the world. But the appearance of the word does not disclose the full meaning of this intricate intellectual phenomenon (Spirkin, 1983). Generally, we can say all people think and thinking is the passageway that leads to philosophy. This argument has led people to reasonably conclude that everyone has the potential of becoming a philosopher. Besides, proponents of this view hold that since we all experience life, we think and reflect on the challenges of life and therefore we develop our individual philosophies of life. Frost (1962) explains the above perspective as he writes:

Your philosophy, then, is the meaning which the world has for you. It is your answer to the question, "why?" having fitted your experiences into the whole, having related them to each other, you say of the world, this is the way things fit together. This is the world as I understand it. This is my philosophy (p.1).

The above is often referred to as the common-sense view of philosophy. It is an attempt to define philosophy as a collection of views or beliefs one or a group of people have about the world and though often held uncritically. In this sense, philosophy is an attitude, a belief or a wish and therefore a product. Based on personal preferences, the worldview conception holds that individuals or a group of people can select a body of thought that they can call theirs. Thus worldview is a system of generalised views of the world, including man's place in it; a view of man's relationship to the world and himself/herself (Spirkin, 1983). Besides posing as an independent existence in the sphere of social consciousness, worldview is individual; with individuals forming their identity by defining their views of the world. However, noteworthy is the understanding that despite the diversity of worldviews there are, in each worldview, some common questions that transcend the particular and therefore are universal in their revelation of a certain unity. For instance, what is reality? How do we come to know reality? What is right or wrong?

To grasp further the understanding of philosophy as worldview, Wolters (1983) explores more the different conceptions of the connection between worldview and philosophy. According to the first conception, worldview "repels" philosophy in that there is an unavoidable tension that exists between "...theoretical philosophy and existential worldview" 
(p.15). In other words, the worldview conception does not accommodate philosophy as an activity that challenges and resists the existing views and beliefs man hold about their life-world. In the second conception, worldview "crowns" philosophy in that "worldview is not alien to philosophy but is instead its highest manifestation" (p. 16). To acknowledge this, proponents of this model look at worldviews that an individual has or a people have. Expressed differently, this model speaks of worldview as the pinnacle and product of the activity of philosophising; that is, to demonstrate that the process of doing philosophy is only evidenced by the end product - the worldview. In this sense, philosophy has a task of combining the conclusions of the different sciences with the human experiences to produce some kind of consistent worldview.

According to the third conception, for Wolters (1983), worldview "flanks" philosophy. In other words, this model views the two as running parallel and therefore should be kept separate. Thus, it is mandatory not to confuse worldview with philosophy and neither should we allow for compromise. To that end, the model holds that we should understand worldview and philosophy as separate entities. The opposite view of the second model is the fourth - that worldview "yields" philosophy. Put differently, the model looks at philosophy as a product of a worldview and not the opposite. Worldview in this sense leads to philosophy; that is, philosophy is an expression of the worldview. Philosophy can only take place in the context of worldview(s). In this context, worldview is a group of perennial problems in which people develop interest and for which philosophers have always sought answers. This leads to an understanding of the duality between philosophy and worldview with the former as the process that not only works on the latter but with the latter being a product of the former.

What then are the implications of this relationship? Is philosophy necessarily a worldview or a worldview necessarily philosophy? Or, should the two never be conflated? What I find interesting is the basic idea that both philosophy and worldview share a cognitive orientation of viewing the world, although they differ in terms of emphasis. While philosophy stresses the universal, abstract and individual nature of viewing, worldview emphasises the specific, concrete and unique character of viewing. In this sense, for Wolters (1983), worldview "... represents a point of view from a particular vantage point, a perspective on things which cannot transcend its own historicity" (p. 18). Thus, a worldview is characterised by being individual, dated and private. However, as indicated earlier on, a worldview may be more than personal. If held by everyone belonging to a nation or a people, it is collective. This does not dissolve its particularity, since its existence does not go beyond the people or culture from which it originates. Thus, we can talk of the Shona worldview, Akan worldview or Sotho worldview, and none of these worldviews can claim their existence in others. In addition, the worldview is more related to the practices specific to a people and it functions within it. In the process, it misses the theoretical component. Thus, it is often considered unscientific unlike philosophy, which, by its theoretical nature, is not particular to culture alone but rather transcends cultures and individuals, thereby giving it a universal character. The question then is: Is it plausible to talk of A's philosophy as A's worldview? I argue that when referring to A's individual thoughts about the individual's unique, permanent and particular world, we are referring to the individual's worldview. In this sense, worldview is equated to philosophy since it is a way of viewing man and the world that results in a world outlook in the first place. Making much the same point, Wiredu (1992) writes that, "Any group of human beings will have to have some world outlook, that is, some general conceptions about the world in which they live and about themselves both as individuals and members of society" (p. 40).

Nevertheless, unless these views are subjected to the process of rigorous, systematic analysis for them to adopt a more theoretical and universal understanding of the world they remain worldview apart from philosophy. They remain a body of ideas, doctrines and beliefs held by an individual and a people and fixed in the context in which they originated. Conversely, can we rightly speak of African philosophy, British philosophy, or Asian when referring to the customs, traditions, ideas and beliefs held by the Africans, British, and Asians, respectively, in their own geographical backgrounds? Are a people's egocentric and unexamined habits of mind classified as "philosophy" or are they simply unarticulated and unsynthesised beliefs disposed to vagueness and contradiction?

From the arguments raised in this section, I would argue that it is a misconception to refer to them as philosophy; they are, rather, worldviews. Misconceptions about the nature and character of philosophy may be attributed to widespread ignorance of what philosophy has achieved through works of great philosophers. Those who are skeptical about the value of philosophy have not bothered to know its subject matter, how it is pursued and what its capabilities are. I now turn to the other conception of philosophy — philosophy as a process.

\subsection{The process conception of philosophy}

The discussion above has exposed the complexity of defining the nature of philosophy. The process view which I will explore in this section looks at philosophy as an activity, "... an activity of thought, an activity of critical and comprehensive thought... an activity which responds to society's demand for wisdom...bringing together all that we know in order to 
obtain what we value..." (Pecorino, 1985). Taken from the position of philosophy as critical and comprehensive thought it implies that the process conception of philosophy involves, among other things:

- Resolving confusion

- Unmasking assumptions

- Testing positions

- Correcting distortions

- Looking for reasons

- Questioning conceptual frameworks

- Broadening experience and dispelling ignorance

- Exploring values

- Fixing beliefs by rational inquiry

- Questing for wisdom (Pecorino, 1985).

To do the above involves asking questions of a special kind about fundamental human problems and then to grapple with them in a precise and accurate way. Philosophising thus involves the articulation and enunciation of some unspoken knowledge; implicit and inferred in human experience. This demands time and a certain level of mental development of the individual. But, the question is: Can all people, including children, meet the demands of philosophising? I argue that not all persons are given to the process of philosophising. Philosophy, in the above categorisation, is not to be confused with its end product. For instance, it is not the questions and issues that define philosophy. Rather, it is the way in which they are dealt with or thought about. It is more about the method of doing philosophy, which, like most activities, requires practice to excel at it. Unlike the worldview conception discussed in the previous section that pays special attention to the historical production of philosophic thoughts, philosophy as a process returns to the Socratic marketplace where the method of inquiry and skill of reasoning are most demanded.

Similarly, Nagel (1987) argues "...the common concern of philosophy is to question and understand very common ideas that all of us use every day without thinking about them" (p. 5). Philosophy will raise fundamental and profound questions about experience so as to explore its meaning and construct from it a coherent approximation of ultimate truth. While philosophy asks questions and offers answers, it does not provide answers which wipe out the initial questions. Instead, it allows us to live with them rationally. While philosophical answers do not solve questions about the existential situation, they assist us in transforming and broadening our own personal view of the world. In justifying the inquisitive character of human being, Savater (2002)has come to the conclusion that "For what is man if not an animal that asks questions and will go on asking them, even after all imaginable answers have been given"( $p$. 7). The question then is if all human beings have a proclivity to question reality, are all questions that they ask philosophical. The philosophical questions will remain contestable and insoluble. So, are children capable of asking philosophical questions; ask questions and find answers through critical and rigorous reflection? This leads me to distinguish the process view of philosophy from most academic disciplines, as demonstrated in its two discernible manifestations: the professional practice of philosophical inquiry, and the amateur practice of philosophical inquiry.

The professional practice of philosophy, which sometimes is referred to as academic philosophy, involves not only grappling with philosophical questions from scratch but accommodates analysing the solutions past philosophers have given to the challenges of their time. For instance, a professional philosopher will attend to some assumptions, beliefs, and doctrines and thoughts that have been handled by thinkers in their tradition or even in traditions that transcend their cultures. For instance, a professional philosopher will subject any thoughts and beliefs to critical scrutiny through rigorous, systematic argumentation. On this view, philosophy becomes a critical, rigorous, systematic and consistent method of engaging with previously held "knowledge". Such a perspective of philosophy is usually the dominant one and the most prestigious one practised in universities and colleges. As Estarellas (2007) puts it, "...in the contemporary world, philosophy as a practice enjoys great health, at least within the boundaries of universities" (n. p.) and this enables it (philosophy) to exist as a relatively free activity. This professional philosophy view has often been criticised for growing apart from life coupled with its increasingly abstract interests away from societal problems. This is despite academic philosophers continuing to produce easily defensible and practically relevant works that draw the attention of a wide readership. Non-philosophers have often accused philosophy of being a perfect example of ivory towerism and irrelevance due to its "... preoccupation with abstract theoretical concerns, with elitism, a priorism, and uninvolvement in the practical affairs of life" (Gyekye, 1997, p. 3); what Onyewuenyi (1991) refers to as "an academic and dehumanised philosophy... highly abstract, lifeless and artificial, emptied of real content... (where) thinking overshadowed existence" (p. 35). In addition, philosophy as a discipline is often criticised for being an exclusive intellectual activity that only excites intellectual well-being of its practitioners. 
While a philosopher, generally, maybe concerned with facts and practices of life, the professional philosopher operates at a rarefied and abstract level. In addition, nearly all philosophers hold their philosophies as joint works with those who initially inspired or provoked them. On such an account, a genuine philosophical investigation is touched off by puzzlement at the enunciations of other philosophies and philosophers. Most of the philosophers come to see new ideas or style of philosophy only because of reacting to the thoughts or products of some other past or contemporary thinkers or persons. To this end, Singer (1995) uses the methodological perspective to define philosophy as, "...a method of enquiring into very fundamental questions that do not yield to the methods of science...this method can be characterised by a form of relentless questioning, in which the answer to one question only leads to a further question, and so on, and on and on" (pp. 1-12).

The model that locates the raw material of philosophy directly in the world and the relations human beings have with their world is sometimes referred to as amateur philosophy: an antonym to the professional model. The model posits the activity of philosophising as being engaged in without necessarily having to refer to the canon of philosophical ideas already existing and crucially, too, without being employed as a philosopher. On this view, Savater (2002) proposes that philosophy is "... an intellectual exercise, not a collection of witty remarks...(or) a catalogue of celebrated views" (p. xii). Nor is it simply repetition of other people's thoughts. Hence, the conclusion that if philosophy is to be studied, it should not only be for the sake of any definite answers to its questions but for the sake of the questions themselves as well (Russell, 1998 ). Questions expand our conception of what is possible, augment our intellectual imagination and reduce the dogmatic assurance which closes the mind against speculation(Russell, 1998 ). However, this position does not deny that philosophers may consciously use others' ideas to support their own.

The above description is an attempt to define philosophy in terms of "doing". However, it is noteworthy to observe that this formal way of doing philosophy acknowledges that we cannot treat "having" a philosophy and "doing" philosophy as independent of each other. I argue that if there was no philosophy (or bluntly worldview) in the personal sense then there would be nothing on which we can employ criticism and reflection, that is, do philosophy. Hence, worldviews are not philosophies. Rather, a philosophical attitude is characterised by tolerance of other views, criticism, inquisitiveness and open-mindedness in search of meaning. While common sense presents the raw material, philosophy is the reflective and critical activity of the mental faculty in processing the availed material. The activity of philosophy is individual in the sense that no two people can philosophise for each other but rather can do philosophy with each other; for example, by entering in a dialogical engagement. But the common denominator between the two dimensions of the process view is the understanding that philosophy is more of an activity that utilises unique skills and methods of thinking to provide practical advice for living (Morris, 1999) with reflection as the most outstanding method of doing philosophy.

Given the two definitions of the process view of philosophy, that is, philosophy as doing, what implications for education can we draw from them? Academic (professional) philosophy is usually the didactic philosophy taught in universities and colleges in which students learn and interpret texts written by great thinkers - past or present. If well executed, this didactic philosophy view does help users to recognise what others have written about philosophical problems at the expense of involving themselves in the engagement of the problems on their own. Hence, Schopenhauer (1985) has observed that:

The man who thinks for himself becomes acquainted with the authorities for his opinions only after he has acquired them and merely as a confirmation of them, while a book philosopher starts with his authorities, in that he constructs his opinions by collecting together the opinions of others; his mind then compares with that of the former as an automaton compares with a living man... This is what determines the difference between a thinker and a mere scholar (p. 91).

This stresses the value philosophy has not only for adults but for younger members of society, that is, children.

As a reaction to the professional perspective of philosophy in schools, the amateur philosophical view draws on the Socratic dialectic originating from Socrates' engagement in argumentation in a persistent and unrelenting analysis of any subject. This position of philosophy explains philosophy not as revealed knowledge by someone who knows everything to someone who knows nothing but rather occurs in an environment of mutuality in which participants "...become accomplices in their mutual submission to the forces of reasons and their mutual rejection of the reasons of force"(Savater, 2002). This is a form of disciplined conversation in which the most commonly accepted position is exposed to a dialogical process with the outcome being a clearer position of the meaning. Of most significance is development of thought through the interplay of ideas. Thus, this perspective of philosophy is the comprehensive pursuit of an issue with sound reasoning and courage to question the conventional. In view of this, philosophy then becomes a dialogical inquiry in which participants not merely accept the views of others but listen and respond to what others think in order to live an examined life. Philosophy in this context is a communal dialogical inquiry facilitated by questioning in search of meaning.

Philosophy may also be considered as a personal attitude toward life and the universe. Such an attitude, it may be 
argued, makes one look at human conditions and their problems in their broad perspective or as part of a larger scheme of things. This thereby characterises a philosopher as someone who faces a state of affairs with composure and reflection, with poise and composure (Titus, 1997). A mature philosophical attitude involves a searching and critical attitude, the open- minded attitude that is expressively demonstrated in the willingness to consider all sides of the matter at hand. It includes a readiness to acknowledge life and the world as they are and to challenge them in all their relationships. In this sense then, philosophising as an activity is not merely about reading and knowing about great philosophical works but about thinking philosophically. Philosophy categorised in this way begins in a wonder, doubt and curiosity and grows out of our developing an awareness of human existential circumstances and the accompanying challenges. Hence, philosophy takes the form of a speculative attitude that does not diminish when faced with the difficult and unresolved human problems. In short, philosophy is analytical and speculative in that it is fundamentally a critical and systematic inquiry into the basic ideas and values that underlie human thought, behaviour and practices. In terms of method, Koka (1998)points out that philosophy "interrogates, analyses and categorises concepts, testing their validity and "sanity' in their representation of human life" (p. 26). In addition, Lawson (2004) proposes that philosophy is an "attempt to say the unsayable" (p. 274) by asking questions, drawing attention to flaws in conventional opinion and seeking to apply rational thought to any argument or claim. In the process of interrogation, analysis and categorisation what is illuminated is that philosophical concepts are universal and eternal and they are neither ethnic nor local. This implies that philosophical concepts in essence never change except only in interpretation and application.

Philosophy, for the Greeks, was a practice of asking questions and finding solutions to problems that are valuable and worth of satisfaction. In general this 'love of wisdom' refers to the tradition of thought which examines the ultimate nature of reality, the general conditions of knowing and good society, the existence of beauty and values and the nature of humanity (Juuso, 2007). In the days when Socrates discussed issues in the marketplace, philosophy was primarily about providing practical guidance for living. Despite the world's great wisdom tradition having evolved into a variety of discourse communities, the central interest of philosophy from pre-Socratic times - how to think critically - remains penetrating and meaningful (Solomon, 2000).

The philosophical method is reflective and critical and therefore involves the attempt to think through one's problems and to face the challenges posed by the universe. Although it might prescribe a rationally reflective way of life, philosophy nevertheless does not concern itself with the business of establishing well-filtered and definite doctrines to guide people's lives. It points up alternative courses of action from which individuals can choose. Thus, philosophy has the potential to offer more for the life of the individual (young or old) and for human society and public affairs. As implied in Plato's allegory of the cave, philosophers have the duty to return to the cave (the darkness where the majority are) to bring enlightenment to the captives in order to save them from ignorance, thereby giving philosophy an instrumental value in human affairs. However, for Socrates and Plato alike, philosophy is also an intrinsically valuable activity. The message of the allegory characterises clearly that philosophical wisdom and insight should be applied to the practical problems of human society.

\section{Particular versus Universal Philosophy}

As has been noted in the preceding discussion, there are apparent contradictions about what philosophy is, but it may be observed that philosophy itself is ambiguous. The main concern of this section is to address Van Hook's (1993) question of whether or not "... philosophy is the product of a universal human reason or is every philosophy in some significant way an expression of the culture which produces it? ... (p. 36). Bodunrin describes the question of what is to count as philosophy as a philosophical question itself (Bodunrin, 1991). However, it must be acknowledged that the particular focus of philosophy is on thinking by keeping an eye on the thinking process, that is, it is thinking about thinking. Philosophy designates, on the one hand, as Janz (2004) sees it, a collection of reflective thinking procedures founded in culture and reason, which rigorously and critically elucidate a life-world. In addition, philosophy is the pursuit to discover the implicit assumptions that we operate on; to consider those assumptions critically; and to improve upon those assumptions by replacing them with enhanced options. Does the relevance of the ideas, insights, arguments and conclusions of philosophers who belong to a particular epoch, culture or societies remain tethered to those times, cultures or societies? To answer this question one needs to turn to whether one perceives philosophical ideas or doctrines as particular, that is, as relative and relevant only to the times and cultures that conceived them, or as universal, that is as going beyond the times and cultures that produced them.

The particularistic attitude recognises the cultural roots of any philosophical system by arguing that all thought is situated in and influenced by its cultural context. One particularist who rejects philosophy as having a universal character is Anyanwu(1987), who insisted that "... philosophy is relative to its basic assumption about the nature of experienced reality as well as its epistemological attitude or method...And furthermore, different assumptions and models of 
experienced reality lead to different philosophical doctrines" (p. 237). In the preceding quotation, Anyanwu seems to be contradicting himself, especially when he considers the relativity of philosophy. Is this piece of philosophy not particular to the agent(s)? If it is also relative then why anyone else ought to be impressed by it? If on the other hand Anyanwu takes it to be universal, then he contradicts with himself.

The tendency to reflect on philosophical questions is part of human nature and it is rooted in man's natural proclivity to know and is informed by the instinct to curiosity. Philosophy is related to culture in the sense in which the philosopher looks at the world from the standpoint of the beliefs and conditions of his life, including those of his people and culture. In addition, Osuagwu (2005) citing Okere's Trilogy of African Philosophy describes the relationship between philosophy and culture and views culture as "the necessary background, ingredient, raw material, vessel, source, nourishment of philosophy" (p. 15). However, cultural particulars are not exclusive of the non-culturally determined criteria (Sogolo, 1993). There are universally shared sets of criteria that are common core to human thought and practice.

Given that philosophy is embroidered by a variety of experiences of different cultures, a variety of philosophical assumptions emerge from the complex universe. It is from the diverse world of cultures that philosophical questions surface. Questions about human suffering, death, the meaning of human life, for instance, will come to human thought after the suffering, pain and death of a relative or friend. This implies that particular lived experiences can invoke questions of universal philosophical concern. As Odera Oruka (1989) argues:

That philosophy is universal does not mean that all the philosophers must have similar methods in philosophy, neither does it mean that all rationally warrantable or objectively granted principles or methods must be identical or that they must establish similar truths. Two separate philosophical methods, both being rational, can be opposed to each other. Similarly, two methods of philosophical inquiry, both using rationally granted and warrantable principles, can come to dissimilar truths (p.134).

Worth noting here is that the themes dealt with in philosophy are universal. How the different cultures trace, interpret and synthesise, and in the end put order and meaning to these themes will differ from culture to culture. On this view, Onyewuenyi concludes, "No culture has the order or the last word" (Onyewuenyi, 1991, p. 38). If what we have said is acceptable, it is possible to talk of a philosophy in a particular context, for example European Philosophy, Asian Philosophy or African Philosophy. This implies that each context has its own way of establishing order. Hence Hegel came to the conclusion that:

"Human beings do not, in certain epochs, merely philosophise in general but there is a definite philosophy which arises among a people and a definite character which filters through the history of the people, is most intimately related to them, thereby constituting their foundation"(Hegel, 1892-1896n.p.).

While there is the difference of approach between one group of philosophers seeing philosophy in terms of its special method and the other in terms of the themes and topics it deals with (content), they are united in the belief that philosophy has an important intellectual purpose in the context of present-day society.

The universalistic view holds that philosophy everywhere shares certain features, concerns and characteristics. This point is underlined by Bodunrin (1991) who holds that "philosophy must have the same meaning in all cultures although the subjects that receive priority and perhaps the method of dealing with them may be dictated by cultural biases and the existential situation within which the philosophers operate"(p. 64-65). The universalistic thesis thus maintains that the relevance of philosophical ideas and thoughts can transcend the limits of the times and places of their authors that produced them. This could be justified by the fact that, irrespective of their cultures and histories, human beings share certain basic values. Values such as friendship, happiness, respect for human life and avoidance of painful experiences are good examples. Although not all human beings may share human experiences or problems, the fundamental everyday goals of humanity can be said to be held, ultimately, in common by all. Consequently, irrespective of people's cultural backgrounds, they are bound to be interested in engaging in philosophical inquiry into such values. Gyekye concludes that:

... the historical-cultural moorings of philosophical ideas and proposals are sufficient evidence of their particularity and of the inappropriateness of applying them universally to other cultures or societies, that those ideas-and the problems that gave rise to them-derive from experiences that are specific to cultures or historical situations, and that, consequently, philosophers unavoidably focus attention on issues and problems that interest them or relate to the experiences of their particular cultures and histories, unconcerned seriously to engage reflectively on the problems and issues of other peoples and cultures (Gyekye, 1997, p. 28)

In sum, any philosophy of a particular culture, like all philosophies produced elsewhere, is characterised by both universality and particularity. There are certain universal values such as the sanctity of human life and truth telling and likewise culturally dependent priorities. Any philosophy as shown above is concerned with interrogating common values irrespective of their places of origin as well as socio-cultural experiences peculiar to a people. 


\section{Conclusion}

As has been observed in the discussion above, the question, "what is philosophy?" is itself a philosophical question to which a universally acceptable answer is difficult, but not impossible, to find. The portraits of philosophy examined above demonstrate that it is easier to do philosophy than discuss it, and to talk about it in some other way than to produce a precise, generally agreed definition. However, philosophers engage themselves in the enterprise of philosophising whether or not it leads to any consensual conclusions. The definitions of philosophy mainly fall into two broad categories, namely philosophy as a technical/academic discipline: philosophy as a process; and philosophy as a worldview - a product. The issue of place cuts to the heart of the question of what philosophy is. The above discussion has raised issues about the universality or particularity of philosophy thereby leading to perennial contestations among scholars for the fertile grassland of meaning of philosophy.

\section{References}

Anyanwu, K. C. (1987). The idea of art in African thought. Contemporary Philosophy: A New Survey, 5, 235-260.

Anyanwu, K. C. (2000). The Problem of Method in African Philosophy. In C.S.Momoh (Ed.), The Substance of African Philosophy (pp. 126-146). Auchi: African Philosophy Project Publication.

Aristotle. (982b ). Metaphysics.

Bauman, Z. (1998). Globalization:The Human Consequences. Cambridge: Polity Press.

Blackburn, S. (2004). Foreword. In H.Carvel \& D.Gamez (Eds.), What Philosophy is : Contemporary Philosophy in Action (pp. xiii). London: Continuum.

Bodunrin, P. O. (1991). The Question of African Philosophy. In T. Serequeberhan (Ed.), African Philosophy: The Essential Readings (pp. 63-86). St Paul, Minnesota: Paragon House.

Estarellas, P. C. (2007). Teaching Philosophy vs Teaching To Philosophise. Philosophy Now- a magazine of ideas Retrieved 16 February 2009 , from http://www.philosophynow.org/issue63/Teaching Philosophy vs Teaching To Philosophise

Fisher, R. (1996). Socratic Education: a new paradigm for philosophical inquiry? Creative and Critical Thinking, 4(1), 1-13.

Frost, S. E. (1962). Basic Teachings of Great Philosophers: A Survey of their basic deas. New York: Doubleday.

Gyekye, K. (1997). Tradition and Modernity: Philosophical reflections on the African experience. New York: Oxford University Press.

Hegel, G. W. F. (1892-1896). Lectures on the History of Philosophy (Selections) Retrieved 26 July 2011, from http://www.class.uidaho.edu/mickelsen/Phil\%20310/ToC/Hegel-Hist\%20of\%20Phil.htm

Hountondji, P. J. (1983). African Philosophy: Myth and Reality. London: Hutchinson University Library for Africa.

Janz, B. (2004). Philosophy as if Place Mattered: Thew Situation of African Philosophy. In H. Carel \& D. Gamez (Eds.), What Philosophy Is (pp. 103-115). London: Continuum.

Juuso, H. (2007). Child,Philosophy and Education: Discussing the intellectual sources of Philosophy for Children. Faculty of Education. University of Oulu. Oulu.

Koka, K. (1998). What is African Philosophy?Concept and Application Contributions of the African and German Philosophies to the Formation and Creation of Communities in Transition (pp. 25-34). Johannesburg.

Lawson, H. (2004). Philosophy as saying the Unsayable. In H. Carel \& D. Gamez (Eds.), What Philosophy Is. London: Continuum.

Lucas, C. (1969). What is Philosophy of Education? . London: Macmillan.

Morris, T. (1999). A comparative study of humanism and pragmatism as they relate to decision-making in instructional development processes. Michigan State University. East Lansing.

Nagel, T. (1987). What does it at all mean? A very short introduction to philosophy. Oxford Oxford University Press.

Odera Oruka, H. (1989). Principles of African Philosophy. In S. B. Oluwole (Ed.), Readings in African Philosophy : An Anthology. Lagos: Meastech Publications.

Omoregbe, J. I. (1998). African Philosophy: Yesterday and Today. In E. Chikwudu Eze (Ed.), African Philosophy: An Anthology. Oxford: Blackwell Publishers.

Onyewuenyi, I. (1991). Is There an African Philosophy. In T. Serequeberhan (Ed.), African Philosophy: The Essential Readings (pp. 29-46). St Pauls, Minnesota: Paragon House.

Osuagwu, I. (2005). Philosophy of Non-Philosophy:Okere's Triology of African Philosophy. In J. Obi Oguejiofor \& G. I. Onar (Eds.), African Philosophy and the Hermaneutics of Culture (pp. 48-69). London: Transactions Publishers.

Oyeshile, O. A. (2008). On Defining African Philosophy: History, Challenges and Perspectives. Human \& Social Sciences Journal, 3(1), 57-64.

Pecorino, P. (1985). A process of philosophy and teaching philosophy Metaphilosophy, 16(1), 80-91.

Plato. (155d). Theætetus.

Russell, B. (1998). The Value of Philosophy. In A. Chrucky (Ed.), The Problems of Philosophy. Oxford: Oxford University Press.

Russell, B. (2005). Problems in Philosophy: The Value of Philosophy. In L. BonJour \& A. Baker (Eds.), Philosophical Problems: An Annotated Anthology. New York: Pearson Longman.

Savater, F. (2002). The questions of life: an invitation to philosophy. Cambridge: Polity Press.

Schopenhauer, A. (1985). On thinking for Yourself (R. Hollingdale, Trans.). In R. Hollingdale (Ed.), Essays and Aphorisms (pp. 89-91). Middlesex: Penguin.

Singer, P. (1995). Coping with Global Change: the need for new values. Critical \& Creative

Thinking, 3(2), 1-12.

Sogolo, G. (1993). Foundations of african Philosophy. Ibadan: ibadan University Press.

Solomon, D. L. (2000). Philosophical Inquiry in Instructional Technology: The forgotten Pathway to learning. Paper presented at the The Association for Educational Communications and Technology, Long Beach, California.

Spirkin, A. (1983). Dialectical Materialism. Moscow: Progress Publishers.

Titus, H. H. (1997). Living Issues in Philosophy. California: Wadsworth Publishing Company.

Van Hook, J. M. (1993). African Philosophy: Its Quest for Identity. Quest, VII(1), 28-43.

Wiredu, K. (1992). On defining African philosophy. In H. Nagl-Docekal \& F.M.Wimmer (Eds.), Postkoloniales Philosophieren; Afrika. (pp. 40-62). Vienna: Oldenburg.

Wolters, A. M. (1983). On the idea of worldview and its relation to philosophy. In P. Marshall, S. Griffioen\&R. J. Mouw (Eds.), Stained Glass (pp. 14-25). Lanham,MD: University Press of America. 